\title{
The Influence of Exposure to Religious Symbols on Out-Group Stereotypes
}

\author{
Irene Razpurker-Apfeld, Lipaz Shamoa-Nir \\ Department of Behavioral Sciences, Zefat Academic College, Safed, Israel \\ Email: irenea@013.net.il
}

Received 19 March 2015; accepted 20 April 2015; published 23 April 2015

Copyright (C) 2015 by authors and Scientific Research Publishing Inc.

This work is licensed under the Creative Commons Attribution International License (CC BY). http://creativecommons.org/licenses/by/4.0/

(c) (i) Open Access

\begin{abstract}
The influence of religious content on out-group stereotypes was examined in two experiments, using supraliminal priming. Jewish and Arab-Muslim students completed a search puzzle by which they were exposed to religious concepts, and then they filled questionnaires assessing their stereotypes. In Study $1(\mathrm{~N}=156)$, priming did not affect out-group stereotypes of Jewish participants. However, exposure to religious symbols had an influence on stereotypes among Muslim participants: They perceived Jewish people as more unpleasant when primed by Jewish symbols, and as more antagonistic when primed by Islamic symbols. Study $2(\mathrm{~N}=110)$ replicated these findings while ruling out the possibility that the null effect found for the Jewish group was due to reduced familiarity with out-group symbols. Thus, for the minority group, incidental exposure to religious concepts contributes to negative out-group stereotypes, and suggests the operation of implicit social cognition. The results also relate to models of stereotype content (Fiske et al., 2002), and motivation and opportunity (Fazio \& Olson, 2014).
\end{abstract}

\section{Keywords}

Priming, Religion, Out-Group Stereotypes, Implicit Attitudes

\section{Introduction}

Most psychological theories of religion assume that religion plays an important role in intergroup relations. Religion can be a source of a wide range of beliefs, attitudes and behaviors toward other individuals (Donahue \& Nielsen, 2005). Psychological research has found complex relationships between measures of religiosity and measures of stereotype and prejudice (Allport, 1954/1979; Allport \& Ross, 1967; Bohman \& Hjerm, 2014; Gorsuch \& Aleshire, 1974; Spilka, Hood, Hunsberger, \& Gorsuch, 2003). Furthermore, some studies have shown that religious motivations have contributed to prosocial achievements, while others have shown that religious 
beliefs may reinforce prejudicial stereotypes and violent conflicts (Herek, 1987; Hunsberger, 1996; Silberman, 2005). A recent study (Ramsay, Pang, Shen, \& Rowatt, 2014) revealed that previous exposure to in-group religious words had increased prejudice toward certain culturally out-group persons. Moreover, these effects were found for both Christians and Buddhists. Still, based on this one direct comparison it is unclear if these priming effects may be generalized to other religions and cultures.

Considering the confusing previous research, it is also not clear to what extent the existence of religious content may act as a potential antecedent to stereotypes and prejudice towards out-groups. Therefore, the purpose of this research is to investigate the influence of evoked religious content on out-group stereotypes of members of Jewish and Muslim groups in a multicultural college in Israel. Below we discuss two theoretical aspects, outgroup stereotypes and implicit attitudes, which play a role in the theoretical framework for our hypotheses.

\subsection{Stereotypes towards Out-Group}

A social stereotype is a mental representation that contains the perceiver's knowledge, beliefs, and expectations about a human group (Dovidio \& Gaertner, 1986) based on generalizations that certain traits or behaviors characterize the members of a social group. Negative Stereotypes can lead to conflicts and hostility between groups (e.g. Stephan, Ybarra, \& Bachman, 1999), discrimination and hatred (Dovidio, Gaertner, Pearson, \& Riek, 2005) and are a potential for racial biases (e.g. Stone \& Moskowitz, 2011). In conflict relations, people tend to develop overly-negative images of the other side and these impressions are often influenced by a social stereotyping process (De Dreu, Yzerbyt, \& Leyens, 1995).

Intergroup relations predict not only the degree of positive or negative stereotypes, but also the content of the stereotypes (Cuddy et al., 2009). According to Fiske and colleagues' stereotype content model (SCM; Fiske, Cuddy, Glick, \& Xu, 2002), stereotype content is predicted by two fundamental dimensions: warmth and competence. In their view, groups with higher social status (e.g. educationally successful) are perceived as having high competence, while warmth, is usually associated with groups that do not compete with the in-group for resources (e.g. land) (Fiske et al., 2002). Furthermore, stereotypes toward out-groups with high social status include appreciation alongside hostility, whereas out-groups perceived as having a lower social status, received stereotypes such as paternalism. In dependencies or cooperation relationship between groups, sometimes affection is predicted (Fiske et al., 2002). Indeed, the warmth and competence dimensions characterize the out-group stereotypes of many social groups from different cultural contexts (Cuddy et al., 2009). Yet, stereotype content should be further examined in an interesting context, suggested in this article, namely, under conditions of religious conflict.

Stereotyping can subtly bias decisions and actions, even in people who consciously do not want to be biased. In fact, stereotypic behavior was demonstrated equally for people scoring high or low on racist attitudes questionnaires (Devine, 1989). One study of stereotypes revealed that when naïve participants were subliminally exposed to photographs of African American rather than those of European American people, they responded to computer errors with more hostility (Bargh, Chen, \& Burrows, 1996). Thus, the automaticity of the hostility stereotype about African Americans generated a corresponding behavior.

The current study was held in a multicultural environment of the Zefat Academic College, in which exposure to out-group and in-group religious symbols occurs on a daily basis. These intergroup relations are set in a broader religious background in the Israeli society, in which the Jewish majority group enjoys high status whereas the Arab minority group has a low status. This social complexity justifies the scrutiny of stereotype content, especially since the intergroup relations are affected by the wider context of the Israeli-Palestinian conflict. Specifically, according to SCM, we assume that the high-status Jewish people should be perceived by Muslim members as stereotypically low in warmth but high in competence. The current study focused on the Muslim group as the religious rival of the Jewish group, since the three different religious groups, which compose the Arab group in the Israeli society, i.e. Muslims, Christians and Druze, have a different cultural identity (Smooha, 2001) and differ in their moral dilemmas (Orland-Barak, Kheir-Farraj, \& Becher, 2013). Moreover, a previous priming study performed in the same setting has shown that the Arab participants are not a coherent group (Shamoa-Nir \& Razpurker-Apfeld, 2013).

As described above, a relationship between group relations and their perceived status (nationality or religion) and stereotypes towards out-group is posited, but the mechanism that leads from the antecedent to the outcome variable is lacking. Below, priming of religious concepts is suggested to fill this role and provide some insight into the process involved here. 


\subsection{Implicit Attitudes and Priming}

Although psychologists have assumed that attitudes function consciously (Greenwald \& Banaji, 1995), over time, due to the possibility that considerable portions of knowledge can be inaccessible to consciousness (Greenwald et al., 2002), researchers have developed new methods of investigation, examining attitudes both directly and indirectly. Indeed, indirect measurement techniques have been successful in situations where participants do not want to reveal their attitudes (Greenwald et al., 2002) and guarantee that measurement will be free, to a large extent, of social desirability (Fazio \& Olson, 2003). Yet, although there is much activity in measuring content accessibility using implicit methods, most of the research focuses on methodological aspects rather than theoretical aspects (Fazio \& Olson, 2003).

An interesting view on implicit attitudes from a theoretical perspective was presented by Greenwald and Banaji (1995) who suggested implicit social cognition as a cognitive structure which includes implicit attitudes. In their view, there are situations in which a person has implicit social cognition, allowing attitudes to implicitly influence behavior, although the person may explicitly deny them. In their associative network theory of implicit attitudes, Greenwald and colleagues (2002) provided consistency and theoretical integration among four important social-cognitive structures: attitude, stereotype, self-esteem and self-concept. Yet, they concluded that the unification they had achieved was limited to implicit measures. They suggested extending the theory to varying situations and social contexts using explicit measures (Greenwald et al., 2002). The present study is concerned with dyadic relations offering a social comparison between members of different religious groups in conflict relations that are somewhat part of a single multicultural grouping. Furthermore, the present study combines explicit measurement of stereotypes following a priming manipulation. Priming was not subliminal, but engagement with religious primes was incidental, thus allowing implicit alteration of attitudes.

Indeed, stereotypes have been shown to have a substantial implicit mode of operation (Greenwald \& Banaji, 1995) and it was additionally supported that stereotypes are made more accessible by a priming procedure. An encounter with a concept may increase subsequent sensitivity to it, so being exposed to stereotypes enables them to be more quickly activated and used in a following situation. In typical studies the participant is primed with concepts from a certain category and thereafter examined for attitudes, decision making or behavior. It has been shown, for example, that when participants were primed with words related to being old, they left the experiment room significantly slower than control participants (Bargh et al., 1996). Note, that while some studies have provided some conceptual replications of such priming effects (e.g., Dijksterhuis, Spears, \& Lépinasse, 2001; Nussinson, Seibt, Häfner, \& Strack, 2010), others have reported null priming effects for direct replications (Doyen, Klein, Pichon, \& Cleeremans, 2012; Shanks et al., 2013).

Focusing on priming of religious concepts, studies have shown it to affect behavior and attitudes. Religious priming induces pro-social behavior but also prejudice. Experimental studies have shown that priming of religious concepts affected pro-social behavior among religious and non-religious people (Ahmed \& Salas, 2008; Pichon, Boccato, \& Sroglou, 2007), and that following subliminal priming of in-group religious concepts, there were significantly more prejudice and negative emotions towards cultural minority out-groups compared to conditions in which neutral concepts were primed (Johnson, Rowatt, \& LaBouff, 2010; Ramsay et al., 2014). Correlational studies have demonstrated that religion is related to both reduction and boost in prejudice (for review see, Hunsberger \& Jackson, 2005). In the present study priming was employed to evoke stereotypes towards members of a religious out-group, thus exploring the conditions under which in-group and out-group religious content (presented visually as words) influences attitudes.

\section{Study 1}

Taken together, we aimed to examine the influence of visually priming religious concepts, representing wellknown religious symbols, on out-group stereotypes. Accordingly, the following was argued:

Hypothesis 1: Based on religious priming literature, priming of religious concepts is expected to affect outgroup stereotypes compared to priming neutral concepts.

Relating to SCM, and given the demographics of the study population according to which there is a connection between the participant's religion: Jewish or Muslim, and group status: majority or minority group (respectively), as well as assuming their competitive relationship, it is hypothesized that:

Hypothesis 2: Participant's religion moderates the relationship between the type of priming (out-group religious concepts or in-group religious concepts) and negative stereotypes as follows: 
Hypothesis 2a: Since the Muslim group in Israel has a low status, the majority Jewish participants' out-group stereotypes are expected to be more positive when primed by Islamic concepts, and to be reflected in traits related to paternalism and warmth.

Hypothesis $2 b$ : Since the Jewish people in the present context are considered to be a high-status competitive out-group, the minority Muslim participants' out-group stereotypes are expected to be more negative when primed by Jewish concepts, especially in traits representing content of low-warmth and hostility.

\subsection{Method}

\subsubsection{Participants}

One hundred fifty six Jewish and Muslim undergraduate students, studying at a multicultural college in Israel, were recruited to participate in the experiment. There were 88 Jewish students (53 women and 35 men) and 68 Muslim students (44 women and 24 men). The age of the Jewish participants ranged between 19 to 51 years ( $M$ $=27, S D=7)$. The age of the Muslim participants ranged between 17 to 41 years $(M=21, S D=4.6)$. On a 1 (non-religious) to 10 (religious) scale, the mean reported religiosity of Jewish participants was $5.7(S D=2.6)$. Mean reported religiosity of Muslim participants was also $5.7(S D=2.3)$.

\subsubsection{Materials}

Word Search Puzzle. The word search puzzle served as the priming task. This task has been used in previous studies (for priming general concepts: Bargh, Gollwitzer, Lee-Chai, Barndollar, \& Trotschel, 2001; for priming neutral and positive religious concepts: Pichon et al., 2007). In this study a Hebrew version was prepared, contrasting concepts from the conflicting religions. A pilot study assured that the chosen words indeed represented the appropriate religions (there was a very high agreement among raters that they represent symbols from Judaism, Islam or neutrality). Each puzzle consisted of 3 critical words and 4 filler words. The task was to find and mark 7 target words specified in a list. These words were embedded in a $9 \times 12$ matrix of letters. They could appear from right to left, left to right, up to down or down to up or diagonally to all directions. The filler words always included flower-pot, telephone, rice and train. The critical words in the Jewish priming condition included: yarmulke, mezuzah and Torah; the critical words in the Islamic priming condition included: veil, Koran and mosque. In the Neutral priming condition pencil-box, table and computer were added. In Hebrew each of the critical words in one condition had a word that matched in length in the other conditions. The locations of the filler and critical words were always the same. To assess the stereotypes of Jewish members toward Muslim members and vice versa, two questionnaires were employed. These questionnaires were developed by Stephan et al. (Stephan, Ageyev, Coates-Shrider, Stephan, \& Abalakina, 1994) and have also a Hebrew version (TurKaspa \& Shwarzwold, 2003—referring to immigrants from Russia and Ethiopia).

Stereotypical Trait Questionnaire-Favorability Rating. Participants had to indicate how favorable each of 16 traits seems to be, using a 10-point scale: from 1 representing "very unfavorable" to 10 representing "very favorable". All participants had to indicate how favorable it is to be, for example, ignorant. Three items (conservative, arrogant and hard working) received vague favorability ratings ranging between 5 to 6 , and were therefore omitted. 6 items were reverse scored, so that unfavorable traits were represented by low ratings. This questionnaire resulted in a satisfactory Cronbach alpha of .851 across participants (for Jewish participants .848 and for Muslim participants .791).

Stereotypical Trait Questionnaire-Percentage Estimate. In this questionnaire participants had to estimate the percentage of Jewish or Muslim members that in their opinion possessed each of the 16 traits, using a 10point scale, representing $10 \%$ increments from $0 \%$ to $100 \%$. A Jewish person, for example, had to estimate the percentage of Muslims that were ignorant, while a Muslim person had to estimate the percentage of Jews. The same 6 items matching the ones from the previous questionnaire were reverse scored.

Stereotype Indices. For each of the 13 traits (per participant), the percentage estimate and favorability rating were multiplied by each other. Higher values of these stereotype indices reflect more negative stereotypes. Previous studies that have used these questionnaires (for example, Stephan, Ybarra, Martinez, Schwarzwald, \& TurKaspa, 1998), have added the products across traits to create a summary stereotype index. Nonetheless, since based on SCM one of the aims of this study was to examine stereotype content and not a unidimensional negative stereotype, and since priming effects may be subtle and masked in a summary index, factor analysis was used to refine the various traits and enable detection of priming effects on distinct content. 
Negative Stereotype Factors. The 13 stereotype indices were submitted to a factor analysis. Principal component analysis (PCA) with orthogonal rotation of Varimax with Kaiser normalization resulted in a 3-factor solution. The first factor captured the unfriendly, unreliable, undisciplined, disrespectful and unclean traits, which had loadings over .65 and as was labeled: "unpleasant". Its psychometric properties are shown in Table 1. The traits that loaded heavily on the second factor were: ignorant, aggressive, unintelligent, clannish and unrestrained. This factor was labeled: "antagonistic". The third factor which was extracted was reflected by a single trait (egoistic), and hence was excluded from further analyses. A summary of the statistics concerning the factors and details about their internal consistency are presented in Table 1.

Next, for each participant two factor scores were extracted using a regression method. Higher values on these scores indicate more negative stereotypes.

\subsubsection{Design}

This was a between-subjects design in which participant's religion and type of priming were the independent variables and the two negative stereotype factor scores were the dependent variables.

\subsubsection{Procedure}

The experiment was conducted in small heterogeneous groups. Participants were randomly assigned to priming of Jewish concepts, Islamic concepts or neutral concepts (for Jewish participants: $N=39, N=28, N=21$, respectively; for Muslim participants: $N=24, N=22, N=22$, respectively). First each participant completed one of the three types of the search puzzles and then filled the questionnaires. A Muslim participant rated Jewish people and a Jewish participant rated Muslim people. Finally, the participants provided some background details about their age, sex, religion and religiosity.

\subsection{Results}

Eight participants were excluded from the analyses: five of them did not fill the questionnaires and three others did not perform the word puzzle properly. Thus, we considered the data of 148 Muslim and Jewish participants. Initially, specific planned comparisons were carried out to compare the baselines of out-group stereotypes of Jewish and Muslim participants. For this purpose a one-way multivariate analysis of variance (MANOVA) was performed only for participants primed by neutral concepts. The effect of participant's religion on the two factor scores, reflecting a combined measure for stereotypical perception, was tested under neutral conditions. Religion had no effect on stereotypical perception (Hotelling's Trace $=.052, F<1$ ). The results confirmed that Jewish and Muslim participants did not differ in their baseline stereotypes, regardless of priming.

Next, to directly examine our hypotheses, participant's religion and type of priming (all three conditions) served as independent variables. The two factor scores served as dependent variables. It was also examined whether these variables were influenced by the participant's sex and religiosity, so the former was entered into the model as an independent variable and the latter as a covariate. Background details of sex and religiosity may be relevant if they interact with priming effects.

Religiosity had no effect on attitudes $(F<1)$, neither did sex [Hotelling's Trace $=.026, F(2,130)=1.677$, $p>$.19], whereas there were significant main effects for religion [Hotelling's Trace $=.08, F(2,130)=5.172, p$ $<.008$ ] and for priming [Hotelling's Trace $=.138, F(4,258)=4.449, p<.003$ ]. These effects were qualified by the interaction between religion and priming [Hotelling's Trace $=.097, F(4,258)=3.113, p<.017$ ]

The interactions between sex and priming and among sex, priming and religion were not significant $(F \mathrm{~s}<1)$.

Table 1. Psychometric properties of negative stereotype factors in Study 1.

\begin{tabular}{|c|c|c|c|c|c|}
\hline \multirow{2}{*}{ Factor } & \multirow{2}{*}{$\begin{array}{c}\text { Traits } \\
\text { (Loadings }>\text {.59) }\end{array}$} & \multirow{2}{*}{$\begin{array}{c}\text { Accounted } \\
\text { Variance (\%) }\end{array}$} & \multicolumn{3}{|c|}{ Internal Consistency (Cronbach’s $\alpha$ ) } \\
\hline & & & Jewish Group & Muslim Group & General \\
\hline Unpleasant & $\begin{array}{l}\text { Unfriendly, Unreliable, Undisciplined, } \\
\text { Disrespectful, Unclean }\end{array}$ & 26.3 & .82 & .84 & .84 \\
\hline Antagonistic & $\begin{array}{l}\text { Ignorant, Aggressive, Unintelligent, } \\
\text { Clannish, Unrestrained }\end{array}$ & 19.39 & .73 & .60 & .68 \\
\hline- & Egoistic & 10.41 & & - & \\
\hline
\end{tabular}


There was a marginally significant interaction between the participant's sex and religion [Hotelling's Trace $=.046, F(2,130)=3.0, p=.053]$. The breakdown of this interaction showed that male and female Muslim participants did not differ in their attitudes toward Jewish people $(F<1)$, but the Jewish participants' attitudes toward Muslim people tended to be affected by the perceiver's sex [Hotelling's Trace $=.06, F(2,85)=2.554, p$ $=.084$ ]. However, since this pattern of results did not involve priming, which was of main concern in this study, this issue was not further pursued.

Thus, the central finding was the significant religion and priming interaction, indicating that stereotypes of Jewish and Muslim participants were differently affected by priming. Additional analyses demonstrated that there were no priming effects for the Jewish group [Hotelling's Trace $=.034, F<1$ ], while the Muslim group was differently affected by the type of prime [Hotelling's Trace $=.226, F(4,110)=3.107, p<.019]$. The separate univariate tests, performed for Muslim participants, revealed that there was a marginally significant priming effect for the "unpleasantness" factor $\left[F(2,57)=3.166, M S E=1.499, p=.050, \eta^{2}=.09\right]$. A post-hoc Duncan analysis indicated that Muslim participants stereotypically perceived Jewish people as more unpleasant when primed by Jewish concepts than when primed by Islamic or neutral concepts $(p<.05)$, as illustrated in Figure 1 (a).

Additionally, a significant priming effect was shown for Muslim participants for the "antagonism" factor [ $F$ $\left.(2,57)=3.266, M S E=.923, p<.046, \eta^{2}=.103\right]$. Duncan analysis indicated the Muslim participants stereotypically perceived Jewish people as more antagonistic when primed by Islamic concepts than when primed by Jewish or neutral concepts $(p<.05)$. This is shown in Figure $1(\mathbf{b})$.

\subsection{Discussion}

Two main results were found in this experiment. First, priming effects were obtained, in accordance with the aforementioned studies from the field of religion priming, thus verifying Hypothesis 1 . Second, and more important, religion mediated priming effects: only Muslim participants were affected by priming, while Jewish participants were not, thus falsifying Hypothesis 2a. Hypothesis $2 \mathrm{~b}$ was partially confirmed. Muslim participants perceived Jewish people as more unpleasant when primed by Jewish concepts. This was expected based on SCM, because the high-status competitive Jewish out-group was perceived as low on warmth (high unpleasantness score), after the Muslim minority members' stereotypes were evoked by the out-group Jewish priming. Indeed

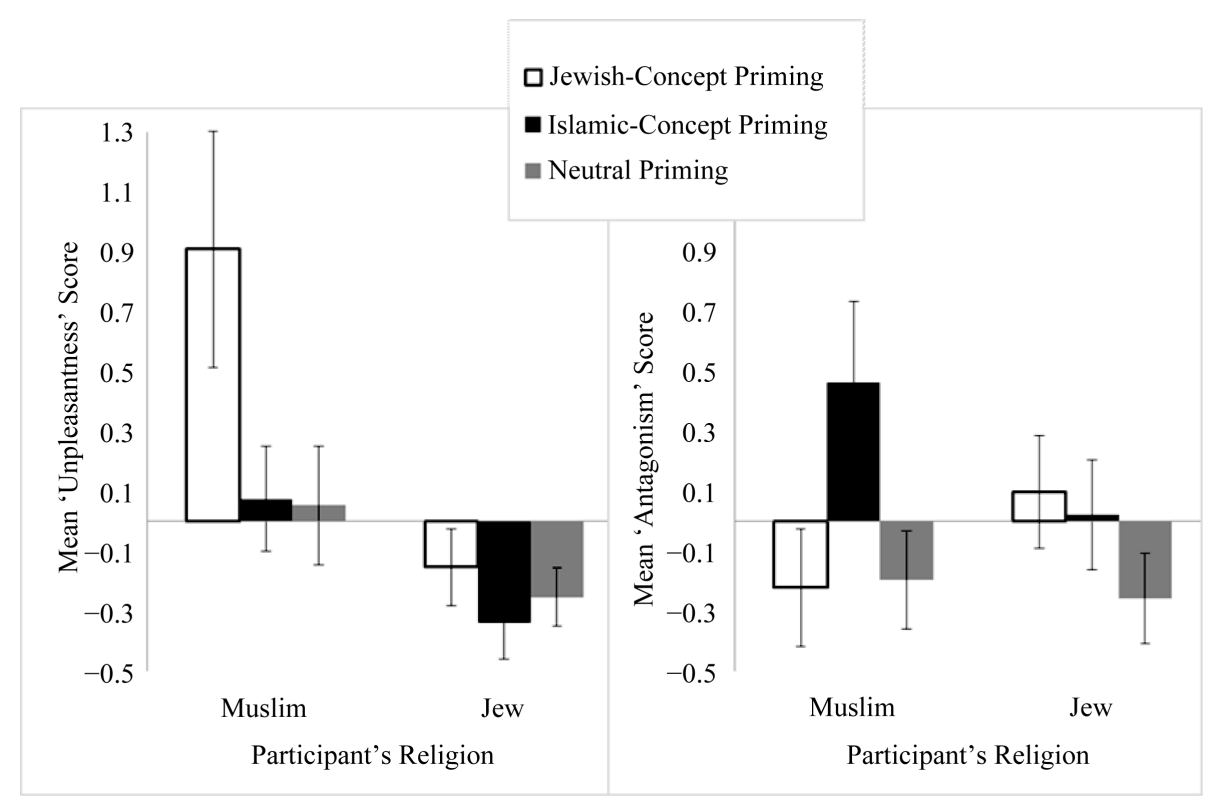

(a)

(b)

Figure 1. Stereotypically perceiving the other as a function of the different priming conditions in Study 1. Panel A refers to perceiving the other as unpleasant and Panel B refers to perceiving the other as antagonist. Higher factor scores represent more negative attitudes. Error bars represent standard error. 
as our hypothesis asserts, Muslim participants also perceived Jews to be hostile or resentful, as reflected by the high antagonism score. However, contrary to the hypothesis, this stereotype was evoked when Muslim individuals were primed by their in-group Islamic concepts, not out-group.

As mentioned, some concerns have been raised about the replicability and robustness of findings in the field of priming (Doyen et al., 2012; Shanks et al., 2013). Hence, we intend to confirm that the religious priming effects in the current study are reliable. Replication is necessary and will be conducted in the next study to search for consistency across effects.

The findings clearly point out that the priming effects were asymmetrical. Minority members are probably more familiar with the out-group world of the majority, rather than the other way around, due to the dominance of the majority in the general culture. In our specific case, it is possible that Muslim individuals know the Jewish world and its symbols better than any knowledge Jewish individuals may have regarding Islamic symbols. Thus, the priming concepts may have met active or well-based suitable representations of Muslim persons about Jewish people. Some of the Jewish participants in this study may have been exposed for the first time to religious Muslim symbols, so priming did not affect the stereotypes of Jewish participants toward Muslim people. This possibility will be further examined in the next experiment.

\section{Study 2}

Study 2 was designed to directly replicate the findings of Study 1 by manipulating in-group and out-group priming conditions while examining the possibility that Jewish persons are less familiar than Muslim persons with out-group symbols. If so, will controlling familiarity moderate the differences in stereotypes between the Jewish and Muslim groups following priming?

Familiarity was tested using self-report questions about either Jewish or Islamic concepts which had been presented at the priming phase. Two types of questions were employed in an attempt to tap different aspects of familiarity. It has been suggested that conceptual knowledge may be characterized by independent dimensions of organizations, some dedicated to perceptual knowledge for each of the different perceptual modalities, and another to representation of non-perceptual knowledge (Caramazza \& Mahon, 2003; Coltheart et al., 1998). Thus, in this study participants were required to estimate their ability to visually recognize religious concepts (perceptual knowledge) and their knowledge about the function of these concepts (non-perceptual knowledge). These two types of questions will hereafter be referred to as "identification" and "function knowledge" questions, respectively.

It was hypothesized that the priming effects found in Study 1 would be replicated. In addition, it was expected to observe priming effects not only for the Muslim group, but also for the Jewish one, after controlling for familiarity with religious concepts.

\subsection{Method}

\subsubsection{Participants}

One hundred and ten Jewish and Muslim undergraduate students from the multicultural college were recruited to participate in this experiment, none of which had taken part in Study 1. There were 53 Jewish students (42 women and 11 men) and 57 Muslim students (43 women and 10 men. Four participants did not provide information about their gender). The age in the Jewish group ranged from 19 to 42 years $(M=27, S D=6.1)$. Mean religiosity in this group was $7.2(S D=2.9)$. The age in the Muslim group ranged from 19 to $29(M=22, S D=2)$. Their mean religiosity was $5.7(S D=1.8)$.

\subsubsection{Materials}

Word Search Puzzle. The exact Hebrew version prepared for Study 1 was used in Study 2 for priming Jewish concepts or Islamic concepts. Neutral priming was not employed in the second study.

Stereotypical Trait Questionnaires. The two parts of the Hebrew version questionnaire were administered in this study, too. The same three items (conservative, arrogant and hard-working) received once again vague favorability ratings and were therefore omitted. The favorability rating questionnaire resulted in a satisfactory Cronbach alpha of .878 across participants (.861 for the Jewish group and .874 for the Muslim group). Stereotype indices were calculated, as described in Study 1, and then negative stereotype factors were computed. The same subscales drawn for Study 1 were computed by specifying two factors for extraction using PCA. The 
structure of these factors was cross-validated. The "unpleasantness" factor was completely congruent with the one of Study 1, and the "antagonism" factor consisted of three of the five same items of the previous study, which highly fit the factor by content. Both factors yielded satisfactory consistency. The psychometric properties of the two factors are presented in Table 2.

Familiarity Questions. Participants were requested to rate the extent to which they were familiar with three religious concepts on a scale ranging from 1 (unfamiliar) to 10 (familiar). Participants primed by Jewish concepts were subsequently inquired about the Jewish critical words, namely, yarmulke, mezuzah and Torah. Participants primed by Islamic concepts (veil, Koran and mosque) were asked about them. For each concept participants had to a) indicate the possibility of visually identifying the concept had they seen it; and b) estimate their extent of knowledge concerning the concept's function. For example, "Had you seen a mezuzah in front of you, to what extent would you have recognized it?", and "What is the extent of your knowledge about the function of a mezuzah?”. Visual identification questions resulted in a Cronbach alpha of .725 across participants (.713 for the Jewish group and .704 for Muslim group), and function knowledge questions resulted in a Cronbach alpha of .742 (.79 and .699 for Jewish and Muslim groups, respectively).

\subsubsection{Design}

For each religion (Jewish or Muslim), type of priming (Jewish vs. Islamic concepts) was the independent variable and the two negative stereotype factor scores were the dependent variables. In addition, the two types of questions concerning familiarity with religious concepts (identification and function knowledge) were treated as covariates.

\subsubsection{Procedure}

Jewish and Muslim participants were randomly assigned to the two priming conditions: Jewish concepts and Islamic concepts (for Jews: $\mathrm{N}=33, \mathrm{~N}=20$, respectively; for Muslims: $\mathrm{N}=26, \mathrm{~N}=31$, respectively). The procedure was basically the same as that in Study 1 . The only addition was that after searching the puzzle and filling the stereotype questionnaires, the participants answered six questions concerning their familiarity with three religious concepts. The experiment ended with the participants providing personal details, as in the previous study.

\subsection{Results}

Eight Muslim participants did not complete the entire word puzzle prior to the questionnaires or failed to fill the questionnaires properly, and therefore were excluded from the sample.

\subsubsection{Familiarity with Religious Concepts}

Jewish participants, as compared to Muslims, reported a higher extent of familiarity with Jewish concepts, as revealed by visual identification questions (means of 9.48 vs. 5.71, for Jewish and Muslim participants, respectively) and by function knowledge questions (means of 9.28 and 5.28 for Jewish and Muslim participants, respectively). These differences between means were significant [for identification questions: $t(26.56)=6.804, p$ $<.001$; for function knowledge: $t(28.29)=7.226, p<.001$ ]. Similarly, Muslim participants, as compared to Jewish participants, reported being significantly more familiar with Islamic concepts as indicated by identification questions [means of 8.55 and 7.65 for Muslim and Jewish participants, respectively; $t(46)=2.101, p<.042$ ] as well as by function knowledge questions [means of 8.42 and 6.82 for Muslim and Jewish participants, respectively; $t(46)=3.887, p<.001$ ] .

As to whether Jewish participants were less familiar with out-group concepts than were Muslim participants, the means of reported familiarity show the opposite: Jewish participants primed by Islamic concepts produced a

\section{Table 2. Psychometric properties of negative stereotype factors in Study 2.}

\begin{tabular}{cccccc}
\hline \multirow{2}{*}{ Factor } & \multirow{2}{*}{$\begin{array}{c}\text { Traits } \\
\text { (Loadings }>\text {.59) }\end{array}$} & $\begin{array}{c}\text { Accounted } \\
\text { Variance (\%) }\end{array}$ & \multicolumn{3}{c}{ Internal Consistency (Cronbach's $\alpha$ ) } \\
\cline { 5 - 7 } Unpleasant & $\begin{array}{c}\text { Unfriendly, Unreliable, Undisciplined, } \\
\text { Disrespectful, Unclean }\end{array}$ & 29.5 & Jewish Group & Muslim Group & General \\
\hline Antagonistic & Aggressive, Unintelligent, Unrestrained & 19.83 & .68 & .88 & .80 \\
\hline
\end{tabular}


mean of 7.65 in identification questions and 6.82 in function questions, while Muslim participants primed by Jewish concepts came up with lower means of 5.71 and 5.28 for identification and function questions, respectively.

\subsubsection{Priming Effects}

Planned comparisons were carried out on the out-group attitudes to examine the priming effects for the Jewish and Muslim groups. The data of 49 Muslim participants were submitted to a multivariate analysis of covariance in which type of priming served as an independent variable and the two factor scores, unpleasantness and antagonism, reflected a combined dependent measure for stereotypical perception. Religiosity of Muslim individuals and their familiarity with the Jewish concepts were entered as covariates. These covariates did not influence stereotypical perception of Muslims $\left(p_{\mathrm{s}}>\right.$.297). Yet, significant priming effects were found for Muslims [Hotelling's Trace $=.178, F(2,43)=3.823, p<.031]$. The separate univariate tests, performed for the Muslim group, revealed that there was a significant priming effect for the "unpleasantness" factor $[F(1,44)=4.267, M S E=$ 1.325, $p<.046, \eta^{2}=.08$ ]. Muslim participants stereotypically perceived Jewish people as more unpleasant when primed by Jewish concepts than when primed by their in-group concepts, as illustrated in Figure 2(a). Additionally, a significant priming effect was obtained for the "antagonism" factor $[F(1,44)=4.522, M S E=.672, p$ $\left.<.040, \eta^{2}=.08\right]$. Figure 2(b) depicts this finding: Muslim persons primed by Jewish concepts significantly perceived Jewish people to be less antagonist compared to Muslim persons primed by in-group concepts.

The multivariate analysis of covariance concerning the 53 Jewish participants resulted in null priming effects (Hotelling's Trace $=.012, F<1$ ), and showed no influence of religiosity or familiarity with Islamic concepts on attitudes $\left(p_{\mathrm{s}}>\right.$.813).

\subsection{Discussion}

Study 2 replicated the general findings of Study 1 . This replication has verified the reliability of the priming effects found for Muslims, hereby reducing the possibility of them reflecting a Type I error. Both studies were conducted at different times with different samples, and yet steady factor structures were found between experiments, and in accordance with the content proposed by SCM. Moreover, the emergent stereotype factors were differentially modified by in-group versus out-group concept priming, and were influenced in an equivalent manner

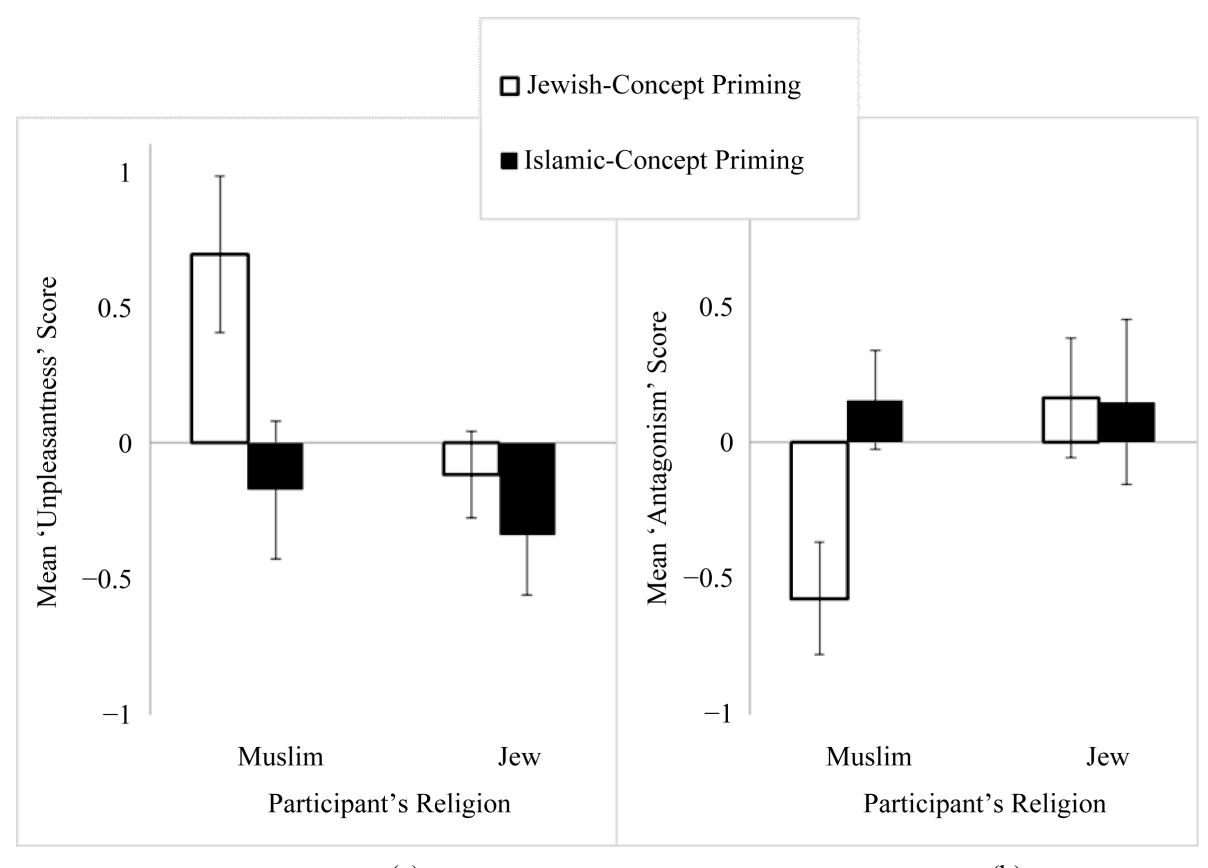

(a)

(b)

Figure 2. Stereotypically perceiving the other as unpleasant (Panel A) or antagonist (Panel B) as a function of the two priming conditions in Study 2. 
in both experiments. Taken together, Muslim participants primed by out-group religious conceptual content (relative to in-group content) stereotypically perceived the high-status Jewish persons as more unpleasant, and Muslim participants primed by in-group concepts (relative to out-group concepts) perceived Jewish persons as their antagonist opponents.

This experiment primarily aimed to examine whether Jewish participants are less familiar than Muslim participants with out-group symbols. Contrary to the hypothesis, the majority group did not claim to be any less familiar with out-group religious concepts than did the minority. Neither their estimated perceptual knowledge nor their estimated non-perceptual knowledge seemed to have reflected any disadvantage relative to the minority. Thus, at least according to self-reports, familiarity cannot account for the asymmetry found in the priming effects between the Muslim and Jewish groups.

\section{General Discussion}

\subsection{Stereotypes and Priming Religious Symbols}

In the present research evidence was obtained for the influence of primed religious concepts on intergroup attitudes and perceptions. As predicted, priming religious symbols influenced negative stereotypes in the context of two religious groups in a conflicted state in Israel. Our findings contribute to the mechanism of social-cognitive structures and attitudes in two facets. The first concerns the process of stereotyping as a consequence of exposure to religious content, and the second concerns intergroup relations and out-group stereotypes alongside their content.

As for the first issue, Muslim and Jewish participants were primed with Islamic and Jewish symbols and it was found that attitudes of Muslim participants were affected negatively when primed by both Jewish and Islamic symbols. The results indicated that not only did the priming manipulation evoke and reflect the existing stereotypes, but it may have also had the power of bringing them to extremes, consistently with implicit social cognition research (Greenwald \& Banaji, 1995; Greenwald et al., 2002). Nevertheless, our priming technique for assessing out-group stereotypes after a short engagement with religious concepts adds important notions to the existing literature. First, we extended the theory of implicit social cognition to a situation in which explicit measurement of attitudes was used. Second, unlike most supraliminal priming techniques requiring participants' intentional focus on the primes, the priming method in the current research necessitated incidental engagement with the primes. Thus, even though priming techniques usually enable a glimpse into genuine attitudes of their beholders, it is not clear whether priming religious symbols in our task reflects the existing out-group stereotypes or a modification of those stereotypes. Specifically, it is unclear if the negative stereotypes held by Muslim people reflect their genuine attitudes or a negative modification triggered by the evoked prime. Similarly, do the null priming effects found for Jewish people reflect their non-stereotypical views or rather their positively modified attitudes?

An alternative model, called the MODE model (Motivation and Opportunity as DEterminants of the attitude behavior relation; Fazio, 1990; Fazio \& Olson, 2014; Olson \& Fazio, 2009), can elucidate our findings. Muslim and Jewish persons may differ in their underlying processes that involve motivation and opportunity and as a consequence react differently to the priming conditions. The model postulates that attitudes can guide behavior in an automatic manner but may also involve controlled components when an individual has the opportunity and motivation to do so. According to Fazio and Olson (2014), if a person has enough time and cognitive resources (opportunity) and is motivated to avoid racial conflict and wishes to seem non-prejudiced, then that person can deliberately alter or counter the influence of the automatically activated attitude. Following this reasoning, it is possible that the Jewish individuals in our study activated controlled processes. The Jewish participants had an opportunity because there was no time pressure during the experiments. In addition, these participants, as a majority in a multicultural environment, may have been motivated to avoid prejudice against Muslim people, thus demonstrating social desirability. The Muslim participants, in contrast, had only opportunity, but as a minority they may have not been motivated to control prejudice. So in line with the MODE model, having just one determinant, i.e. opportunity with no motivation, enabled the operation of automatic processes, allowing the evoked attitudes to be spontaneously reflected in the Muslim participants' reported stereotypes.

The second theoretical facet that our findings relate to is the role that stereotypes have in group relations. In consistency with Fiske and colleagues’ SCM (Fiske et al., 2002), Muslim persons perceived Jewish people to be rather unpleasant as revealed by the neutral condition, and when primed by Jewish concepts this unpleasantness 
stereotype was still more negative. Muslim persons perceived Jewish people as sociable in the neutral condition; however, following Islamic priming Muslim individuals stereotypically perceived Jewish people as antagonistic. Yet, the result, according to which only Muslim participants (but not Jewish ones) expressed more negative perceptions toward the Jewish group when preceded by religious content, requires further investigation. In race relations, previous studies have indicated that categorizing others as members of an out-group, automatically activates negative evaluations and emotions. For instance, European American participants responded faster to negative adjectives when preceded by photos of African Americans, while the negative responses of African American participants were facilitated when preceded by photos of European Americans (Fazio, Jackson, Dunton, \& Williams, 1995). Another study showed that even after getting used to unfamiliar faces, amygdala activation, reflecting threat response, decreased for racial in-group faces but not for out-group faces (Hart et al., 2000).

The present study suggests that Muslim participants perceived Jewish people as members of a religious outgroup, characterized by unpleasantness and antagonism, whereas Jewish participants were not affected by priming. This finding raises the question of the connection between a person's self-image and attitudes towards members of a rivalry group. As argued by Greenwald and colleagues (2002), there is a consistency between the four important social-cognitive structures: attitude, stereotype, self-esteem and self-concept. It has been shown, for example, that when a self-image is threatened, people tend to stereotype the minority group, as a strategy to restore their self-image (Spencer, Fein, Wolfe, Fong, \& Duinn, 1998). Thus, the differences between the Jewish and Muslim groups that were found in this study may be partially explained by their social status. It is possible that Muslim participants, as part of the minority group, experience a threat to their self-image and reveal more negative stereotypes towards Jewish people. Since the Jewish praticipants' self-image may have not been threatened in the context of this study, their negative stereotypes did not emerge. To further develop this idea, measurements should be expanded to mutual perceptions concerning threat perception and its possible involvement in the process of religious content priming and attitudes.

Another matter which deserves attention, relates to the finding that Muslim participants primed by their ingroup religious concepts perceived Jewish people as relatively antagonistic, and Muslim participants primed by their out-group religious concepts perceived Jewish people as unpleasant. This unexpected difference indicates that the involvement of religious content in forming attitudes is much more complicated than has been previously suggested. It is possible that being primed by either in-group or out-group concepts stresses the contrast between opponent religions. Indeed, due to the history of hostile relations between Arabs and Jews in Israel, these groups may hold "us versus them" prejudices (Bar-Tal, 1996). Although research has pointed out to complex and varied sets of relationships between personal religiosity and prejudice indicators (Batson \& Stocks, 2005) consistently with other studies (Ahmed \& Salas, 2008; Pichon et al., 2007), none of the effects in this study was involved with religiosity. Thus, the mechanism underlying the influence of the type of religious concepts (in-group or out-group) on stereotypes remains unclear. Nonetheless, our findings do contribute to research showing that religions affect the formation of prejudicial out-group stereotypes and violent conflicts (Herek, 1987; Hunsberger, 1996; Silberman, 2005).

\subsection{Applications}

The above findings may have some important implications in the field of group conflict solving, particularly concerning religious stereotyping and tension. These results can be applied in the compilation of training programs on communication by focusing on cognitive aspects of attitudes, thereby considering the influence of being exposed to religious symbols and its effects on stereotypes.

In a multicultural environment it seems that stereotyping can be reduced by raising awareness to the automaticity of cognitive processes. Since stereotypes reflected in disputes may grow worse, hurt communication between people and groups and may escalate and heighten negative emotions and tension (Rubin, Pruitt, \& Kim, 1994), it is important to find ways to modify stereotypes and thus reduce tension.

\subsection{Limitations and Future Research}

In spite of the study's outcomes, generalizing the results to other populations is limited for a number of reasons. Although the group setting, in which the participants were tested, included both in-group and out-group members equivalently to everyday experience in the college, this situation doesn't necessarily represent the participants' attitudes in other situations. The presence of the out-group members may have influenced the answers of 
both Muslim and Jewish participants. Yet, this limitation does not weaken the pattern of the results: Muslim persons' negative attitudes were nonetheless unveiled and were clearly affected by the priming manipulation. As for the Jewish participants, being the major ethnic group in Israel, did not reveal negative attitudes towards Muslims, reflecting motivation and social desirability effects.

Future research should examine whether the null effect found for Jewish participants is genuine or is due to their motivation to control prejudice. We suggest measuring attitudes after subliminal priming, so that participants would gain less awareness to the process of activating their attitudes and find it difficult to modify them. Another possibility is not to verbally prime religious symbols, but to do so by using pictures. Since visual and verbal information may be coded through separate systems (Paivio, 1986) they may result in differential priming effects.

In addition, because it is known that stereotypes are influenced by deeper feelings such as threat, and by various situational factors which increase stereotype levels, this should be further examined. One possibility would be not to settle for a general measure of stereotype but rather to carry out a number of measures of attitudes, and to differentiate between attitudes and actual behavior or behavior intention.

\section{Conclusion}

This study showed that a simple priming technique is an effective tool for evoking stereotypes, at least for a short duration. Incidental exposure of people from the minority group to religious concepts, such as clothing or holy books, may contribute to perceiving the opponent in a more negative manner than otherwise. In addition, sensitivity was found to stimuli of one's own religion and also to those of one's rival's religion, and together they widen the gap between the in-group and out-group relations. Future research should specify the conditions under which religious priming operates and to what extent its effects last.

\section{Acknowledgements}

This research was conducted at the Zefat Academic College and was supported by the "Zefat Center for Studying Cultures in the Galilee”.

\section{References}

Ahmed, A. M., \& Salas, O. (2008). In the Back of Your Mind: Subliminal Influences of Religious Concepts on Prosocial Behavior. Working Papers in Economics, 331, 1-25. http://econpapers.repec.org/RePEc:hhs:gunwpe:0331

Allport, G. W. (1979). The Nature of Prejudice. Reading, MA: Addison-Wesley. (Original Work Published in 1954).

Allport, G. W., \& Ross, J. M. (1967). Personal Religious Orientation and Prejudice. Journal of Personality and Social Psychology, 5, 432-433. http://dx.doi.org/10.1037/h0021212

Bargh, J. A., Chen, M., \& Burrows, L. (1996). Automaticity of Social Behavior: Direct Effects of Trait Construct and Stereotype Activation on Action. Journal of Personality and Social Psychology, 71, 230-244. http://dx.doi.org/10.1037/0022-3514.71.2.230

Bargh, J. A., Gollwitzer, P. M., Lee-Chai, A., Barndollar, K., \& Trotschel, R. (2001). The Automated Will: Nonconscious Activation and Pursuit of Behavioral Goals. Journal of Personality and Social Psychology, 81, 1014-1027. http://dx.doi.org/10.1037/0022-3514.81.6.1014

Bar-Tal, D. (1996). Development of Social Categories and Stereotypes in Early Childhood: The Case of “The Arab” Concept Formation, Stereotype and Attitudes by Jewish Children in Israel. International Journal of Intercultural Relations, 20, 341-370. http://dx.doi.org/10.1016/0147-1767(96)00023-5

Batson, C. D., \& Stocks, E. L. (2005). Religion and Prejudice. In J. F. Dovidio, P. Glick, \& L. A. Rudman (Eds.), On the Nature of Prejudice: Fifty Years After Allport (pp. 413-429). Malden, MA: Blackwell Publishing. http://dx.doi.org/10.1002/9780470773963.ch25

Bohman, A., \& Hjerm, M. (2014). How the Religious Context Affects the Relationship between Religiosity and Attitudes towards Immigration. Ethnic and Racial Studies, 37, 937-957. http://dx.doi.org/10.1080/01419870.2012.748210

Caramazza, A., \& Mahon, B. Z. (2003). The Organization of Conceptual Knowledge: The Evidence from Category-Specific Semantic Deficits. Trends in Cognitive Sciences, 7, 354-361. http://dx.doi.org/10.1016/S1364-6613(03)00159-1

Coltheart, M., Inglls, L., Cupples, L., Michie, P., Bates, A., \& Budd, B. (1998). A Semantic Subsystem of Visual Attributes. Neurocase: The Neural Basis of Cognition, 4, 353-370. http://dx.doi.org/10.1080/13554799808410632

Cuddy, A. J., Fiske, S. T., Kwan, V. S., Glick, P., Demoulin, S., Leyens, J. P. et al. (2009). Stereotype Content Model across 
Cultures: Towards Universal Similarities and Some Differences. British Journal of Social Psychology, 48, 1-33. http://dx.doi.org/10.1348/014466608X314935

De Dreu, C. K., Yzerbyt, V. Y., \& Leyens, J. P. (1995). Dilution of Stereotype-Based Cooperation in Mixed-Motive Interdependence. Journal of Experimental Social Psychology, 31, 575-593. http://dx.doi.org/10.1006/jesp.1995.1026

Devine, P. G. (1989). Stereotypes and Prejudice: Their Automatic and Controlled Components. Journal of Personality and Social Psychology, 56, 5-18. http://dx.doi.org/10.1037/0022-3514.56.1.5

Dijksterhuis, A., Spears, R., \& Lépinasse, V. (2001). Reflecting and Deflecting Stereotypes: Assimilation and Contrast in Impression Formation and Automatic Behaviour. Journal of Experimental Social Psychology, 37, 286-299. http://dx.doi.org/10.1006/jesp.2000.1449

Donahue, M. J., \& Nielsen, M. E. (2005). Religion, Attitudes, and Social Behavior. In R. F. Paloutzian, \& C. L. Park (Eds.), Handbook of the Psychology of Religion and Spirituality (pp. 274-291). New York: Guilford.

Dovidio, J. F., \& Gaertner, S. L. (1986). Prejudice, Discrimination, and Racism: Historical Trends and Contemporary Approaches. In J. F. Dovidio, \& S. L. Gaertner (Eds.), Prejudice, Discrimination and Racism (pp. 1-34). Orlando, FL: Academic Press.

Dovidio, J. F., Gaertner, S. L., Pearson, A. R., \& Riek, B. M. (2005). Social Identities and Social Context: Attitudes and Personal Wellbeing. In S. R. Thye, \& E. J. Lawler (Eds.), Advances in Group Processes: Social Identification Processes in Groups (pp. 231-260). Oxford: Elsevier. http://dx.doi.org/10.1016/S0882-6145(05)22009-X

Doyen, S., Klein, O., Pichon, C. L., \& Cleeremans, A. (2012). Behavioral Priming: It's All in the Mind, but Whose Mind? PLoS ONE, 7, e29081. http://dx.doi.org/10.1371/journal.pone.0029081

Fazio, R. H. (1990). Multiple Processes by Which Attitudes Guide Behaviour: The MODE Model as an Integrative Framework. In M. P. Zanna (Ed.), Advances in Experimental Social Psychology (Vol. 23, pp. 75-109). New York: Academic Press.

Fazio, R. H., Jackson, J. R., Dunton, B. C., \& Williams, C. J. (1995). Variability in Automatic Activation as an Unobtrusive Measure of Racial Attitudes: A Bona Fide Pipeline? Journal of Personality and Social Psychology, 69, 1013-1027. http://dx.doi.org/10.1037/0022-3514.69.6.1013

Fazio, R. H., \& Olson, M. A. (2003). Implicit Measures in Social Cognition Research: Their Meaning and Uses. Annual Review of Psychology, 54, 297-327. http://dx.doi.org/10.1146/annurev.psych.54.101601.145225

Fazio, R. H., \& Olson, M. A. (2014). The MODE Model: Attitude-Behaviour Processes as a Function of Motivation and Opportunity. In J. W. Sherman, B. Gawronski, \& Y. Trope (Eds.), Dual Process Theories of the Social Mind (pp. 155171). New York: Guilford.

Fiske, S. T., Cuddy, A. J., Glick, P., \& Xu, J. (2002). A Model of (Often Mixed) Stereotype Content: Competence and Warmth Respectively Follow from Perceived Status and Competition. Journal of Personality and Social Psychology, 82, 878-902. http://dx.doi.org/10.1037/0022-3514.82.6.878

Gorsuch, R. L., \& Aleshire, D. (1974). Christian Faith and Ethnic Prejudice: A Review and Interpretation of Research. Journal for the Scientific Study of Religion, 13, 281-307. http://dx.doi.org/10.2307/1384759

Greenwald, A. G., \& Banaji, M. R. (1995). Implicit Social Cognition: Attitudes, Self-Esteem, and Stereotypes. Psychological Review, 102, 4-27. http://dx.doi.org/10.1037/0033-295X.102.1.4

Greenwald, A. G., Banaji, M. R., Rudman, L. A., Farnham, S. D., Nosek, B. A., \& Mellott, D. S. (2002). A Unified Theory of Implicit Attitudes, Stereotypes, Self-Esteem, and Self-Concept. Psychological Review, 109, 3-25. http://dx.doi.org/10.1037/0033-295X.109.1.3

Hart, A. J., Whalen, P. J., Shin, L. M., McInerney, S. C., Fischer, H., \& Rauch, S. L. (2000). Differential Response in the Human Amygdala to Racial Outgroup vs. Ingroup Face Stimuli. NeuroReport, 11, 2351-2354. http://dx.doi.org/10.1097/00001756-200008030-00004

Herek, G. M. (1987). Religious Orientation and Prejudice: A Comparison of Racial and Sexual Attitudes. Personality and Social Psychology Bulletin, 13, 34-44. http://dx.doi.org/10.1177/0146167287131003

Hunsberger, B. (1996). Religious Fundamentalism, Right-Wing Authoritarianism, and Hostility toward Homosexuals in Non-Christian Religious Groups. International Journal for the Psychology of Religion, 6, 39-49. http://dx.doi.org/10.1207/s15327582ijpr0601_5

Hunsberger, B., \& Jackson, L. M. (2005). Religion, Meaning, and Prejudice. Journal of Social Issues, 61, 807-826. http://dx.doi.org/10.1111/j.1540-4560.2005.00433.x

Johnson, M. K., Rowatt, W. C., \& LaBouff, J. (2010). Priming Christian Religious Concepts Increases Racial Prejudice. Social Psychological and Personality Science, 1, 119-126.

Nussinson, R., Seibt, B., Häfner, M., \& Strack, F. (2010). Come a Bit Closer: Approach Motor Actions Lead to Feeling Similar and Behavioural Assimilation. Social Cognition, 28, 40-58. http://dx.doi.org/10.1521/soco.2010.28.1.40 
Olson, M. A., \& Fazio, R. H. (2009). Implicit and Explicit Measures of Attitudes: The Perspective of the MODE Model. In R. E. Petty, R. H. Fazio, \& P. Briñol (Eds.), Attitudes: Insights from the New Implicit Measures (pp. 19-64). Mahwah, NJ: Erlbaum.

Orland-Barak, L., Kheir-Farraj, R., \& Becher, A. (2013). Mentoring in Contexts of Cultural and Political Friction: Moral Dilemmas of Mentors and Their Management in Practice. Mentoring \& Tutoring: Partnership in Learning, 21, 76-95. http://dx.doi.org/10.1080/13611267.2013.784060

Paivio, A. (1986). Mental Representations: A Dual Coding Approach. New York: Oxford University Press.

Pichon, I., Boccato, G., \& Sroglou, V. (2007). Nonconscious Influences of Religion on Prosociality: A Priming Study. European Journal of Social Psychology, 37, 1032-1045. http://dx.doi.org/10.1002/ejsp.416

Ramsay, J. E., Pang, J. S., Shen, M. J., \& Rowatt, W. C. (2014). Rethinking Value Violation: Priming Religion Increases Prejudice in Singaporean Christians and Buddhists. International Journal for the Psychology of Religion, 24, 1-15. http://dx.doi.org/10.1080/10508619.2012.761525

Rubin, J. Z., Pruitt, D. G., \& Kim, S. H. (1994). Social Conflict: Escalation, Stalemate, and Settlement (2nd ed.). New York: McGraw-Hill.

Shamoa-Nir, L., \& Razpurker-Apfeld, I. (2013). The Influence of Exposure to Nationality Concepts on Stereotypes among Jews and Arabs in Israel. Proceedings of the Jerusalem International Conference on Neural Plasticity and Cognitive Modifiability, Jerusalem, 2-5 June 2013.

Shanks, D. R., Newell, B. R., Lee, E. H., Balakrishnan, D., Ekelund, L., Cenac, Z. et al. (2013). Priming Intelligent Behaviour: An Elusive Phenomenon. PLoS ONE, 8, e56515. http://dx.doi.org/10.1371/journal.pone.0056515

Silberman, I. (2005). Religion as a Meaning System: Implications for the New Millennium. Journal of Social Issues, 61, 641-663. http://dx.doi.org/10.1111/j.1540-4560.2005.00425.x

Smooha, S. (2001). Jews-Arabs Relationship. In E. Yaar, \& Z. Shavitt (Eds.), Trends in the Israeli Society (pp. 231-356). Tel-Aviv: The Open University. (In Hebrew)

Spencer, S. J., Fein, S., Wolfe, C. T., Fong, C., \& Duinn, M. A. (1998). Automatic Activation of Stereotypes: The Role of Self-Image Threat. Personality and Social Psychology Bulletin, 24, 1139-1152. http://dx.doi.org/10.1177/01461672982411001

Spilka, B., Hood Jr., R. W., Hunsberger, B., \& Gorsuch, R. (2003). The Psychology of Religion: An Empirical Approach (3rd ed.). New York: Guilford.

Stephan, W. G., Ageyev, V., Coates-Shrider, L., Stephan, C. W., \& Abalakina, M. (1994). On the Relationship between Stereotypes and Prejudice: An International Study. Personality and Social Psychology Bulletin, 20, 277-284. http://dx.doi.org/10.1177/0146167294203005

Stephan, W. G., Ybarra, O., \& Bachman, G. (1999). Prejudice toward Immigrants: An Integrated Threat Theory Analysis. Journal of Applied Social Psychology, 29, 2221-2237. http://dx.doi.org/10.1111/j.1559-1816.1999.tb00107.x

Stephan, W. G., Ybarra, O., Martinez, C., Schwarzwald, J., \& Tur-Kaspa, M. (1998). Prejudice toward Immigrants to Spain and Israel: An Integrated Threat Theory Analysis. Journal of Cross-Cultural Psychology, 29, 559-576. http://dx.doi.org/10.1177/0022022198294004

Stone, J., \& Moskowitz, G. B. (2011). Non-Conscious Bias in Medical Decision Making: What Can Be Done to Reduce It? Medical Education, 45, 768-776. http://dx.doi.org/10.1111/j.1365-2923.2011.04026.x

Tur-Kaspa, S. M., \& Schwarzwald, J. (2003). Perceived Threat and Prejudice in Three Domains of Intergroup Tension in Israeli Society. Megamot, 42, 549-584. (In Hebrew) 